\title{
Technical note: Methodological and feed factors affecting prediction of ruminal degradability and intestinal digestibility of essential amino acids
}

\author{
Robin R. White, ${ }^{*}$ Paul J. Kononoff, $†$ and Jeffrey L. Firkins $\ddagger^{1}$ \\ *Department of Dairy Science, Virginia Tech, Blacksburg 24060 \\ †Department of Animal Science, University of Nebraska, Lincoln 68583 \\ ‡Department of Animal Sciences, The Ohio State University, Columbus 43210
}

\begin{abstract}
We hypothesized that ruminal degradability of essential AA (EAA) and the intestinal digestibility of the ruminally undegraded EAA residue in feeds could be evaluated in a meta-analysis. The objective was to characterize methodological factors for ruminal incubation (time of incubation of feed in situ) and method of simulating digestion of the ruminally undegraded AA (incubation of residue in digestive enzymes in vitro or in mobile bags inserted into the duodenum). To increase numbers of observations, feeds were categorized before ANOVA. An approach is described to predict differential ruminal degradability (or undegradability) of individual EAA by normalizing them as a proportion of total AA (TAA) degradability (undegradability) and similarly to normalize the intestinal digestibility of EAA using TAA. Interaction of feed category with individual EAA justifies future studies with a broader range of feeds and more replication within feed to bolster this approach. With broader data, the approach to normalize EAA as a proportion of TAA should allow a better defined EAA library to be integrated with more robust CP databases (that can be updated with specific feed information from more routine laboratory analyses) in dairy supply-requirement models.
\end{abstract}

Key words: essential amino acid supply, dairy cow, ruminal degradability, intestinal digestibility

\section{Technical Note}

Treatment means were collected from a series of papers assessing RUP among a variety of studies (White et al., 2017) while simultaneously assessing these studies for intestinally digested RUP (dRUP) with the objectives to collect degradability and digestibility coefficients for EAA among individual feeds. All included

Received September 16, 2016.

Accepted November 7, 2016.

${ }^{1}$ Corresponding author: firkins.1@osu.edu studies had pre-incubation of feeds in the rumen, which is not important for predicting total-tract digestibility of EAA for all feeds but is important for starchy feeds or raw legumes to deactivate trypsin inhibitor (Fathi Nasri et al., 2007). Some feeds were incubated for multiple time points, but all had 12 or $16 \mathrm{~h}$ in common. When both 12 and $16 \mathrm{~h}$ were reported, values from 16 -h residues were recorded, as justified by Boucher et al. (2009a). These residues were exposed to the animal's digestive enzymes in mobile bags (Hvelplund, 1985) inserted into the duodenum and retrieved from an ileal cannula (only 1 report in our database) or mostly from the feces, which makes a negligible difference (Boila and Ingalls, 1994); the alternative approach incubated the ruminally undegraded residue in a cocktail of digestive enzymes in the original (Calsamiglia and Stern, 1995) or modified (Gargallo et al., 2006) 3-step in vitro procedure.

For inclusion, ruminal degradability or intestinal digestibility coefficients had to be reported or could be calculated from reported EAA disappearance data (see Supplemental Tables S1 and S2, https://doi. org/10.3168/jds.2016-12008, for references and summary statistics, respectively). Coefficients for individual AA (AAi) were (mass of initial AAi minus mass of residue $\mathrm{AAi}$ )/mass of initial $\mathrm{AAi}$ and converted to a percentage. For ruminal degradability, initial AA were from the feed and residue were after 12- or 16-h incubation in situ; for intestinal digestibility, the 12- or 16-h incubation residues were the initial $\mathrm{AA}$, and residue was the mass of AAi after recovery of mobile bags or filtration after in vitro disappearance in digestive enzymes. From these papers, barley silage from Taghizadeh et al. (2005) was removed as an outlier (EAA digestibility ranged between 22 and $83 \%$ for Phe and Met, respectively, so least squares adjustment of means was too sensitive with this low replication of feeds). Intestinal digestibilities for all feeds were removed from 3 studies (Harstad and Prestløkken, 2000; Ljøkjel et al., 2000; Harstad and Prestløkken, 2001) because the authors discussed mobile bags potentially having higher than 
expected disappearance values (generally 95 to $100 \%$ ) because of a slightly larger pore size (15 vs. the recommended $11 \mu \mathrm{m}$ pore size). When these studies were included, the least squares means slightly exceed $100 \%$ AAi digestibility for a few feeds. Because only 4 studies reported Trp, many of which were $100 \%$ because of low Phe recovery (Boucher et al., 2009c), this EAA could not be assessed satisfactorily. Most but not all studies indicated that Met was protected from oxidation; for those that did not protect it (1 study) or did not report doing so (2 used in ruminal degradability but not intestinal digestibility), the assumption is that feed and all residues have similar (even if lower than had they been protected) recoveries of Met. After all of these criteria were met, the ruminal degradability and intestinal digestibility of EAA of individual feeds in Supplemental Tables S3 and S4 (https://doi.org/10.3168/jds.201612008) were the source data for the meta-analysis.

Several authors reported AA profiles of residue divided by initial AA profiles in feeds. Although such a ratio is a logical presentation of how ruminal or intestinal disappearance varied among individual AA within different feeds under the conditions of that study, this approach does not produce a unique solution to be used in a system designed to predict AA supply. That is, an individual AA degradability or digestibility cannot be directly computed from these ratios and vice versa. Our objectives were to integrate results for AAi into a more robust system derived from the much larger $\mathrm{CP}$ database. Because of incomplete recovery of AA during analysis or from nonprotein $\mathrm{N}$, the total sum of all AA (TAA) is less than $100 \%$, with the notable exception of blood meal (Paz et al., 2014). In our database, reported TAA ranged between 78 and $107 \%$ of CP among feeds. Because percentage $\mathrm{N}$ disappearance is a weighted mean of the disappearance of all $\mathrm{N}$ sources, disappearance of TAA [(mass of TAA initially minus mass of TAA in residue)/mass of TAA initially, converted to a percentage] should be highly correlated with $\mathrm{N}$ disappearance. Using Proc CORR of SAS (version 9.3, SAS Institute Inc., Cary, NC), Pearson coefficients between the degradability or digestibility coefficients of TAA versus $\mathrm{N}$ were $\mathrm{r}=0.95,0.99,0.90$, and 0.99 for ruminal degradabilities at 12 and $16 \mathrm{~h}$ and for intestinal digestibilities as assessed with mobile bags and in vitro, respectively (all $P<0.001$ ). Supplemental Figure S1 (https://doi. org/10.3168/jds.2016-12008) depicts regressions (coefficients derived from Proc REG of SAS), which shows more variation with variables from studies using mobile bags than those using in vitro. If combined into one regression and one outlier (outside of the regression's confidence interval from SAS's fit plot) was removed, the linear regression coefficient was $0.95(\mathrm{SEM}=0.05$; data not shown). Because most reports documented close agreement between TAA and CP, these results are more likely a result of variability and unbalanced representative of feed types or processing methods among approaches. Fathi Nasri et al. (2007) noted some variation in the relationship between TAA and $\mathrm{N}$ digestibility among studies. If trypsin inhibitor was active or proteins were heat-damaged, digestibility of Arg and Lys (both with extra amino groups) could be depressed more severely than other AA, thereby lowering N more than TAA. Although Lys digestibility in cecectomized roosters can be dampened by intentional heating (Boucher et al., 2009b), the original 3-step procedure (used by some studies herein) was less highly correlated with in vivo (cecectomized roosters) than the modified procedure (Boucher et al., 2009c). Even so, in feeds they tested, TAA and CP digestibilities were closely related. Because TAA helps correct for internal sources of error associated with AA analysis (e.g., hydrolysis and quantification differences), we interpret these plots to strongly support the usage of TAA (i.e., the weighted average of recovered AA) as a valid proxy for $\mathrm{N}$ (or CP) and thus a normalizer for integration into a system that estimates RUP and dRUP.

Incorporating AA degradability or digestibility data into dairy nutrition supply-requirement models is a challenge because even an exhaustive literature search such as ours yields an incomplete database with inadequate replication from important feeds used in the field. Because of the limitation of observations needed for a robust data set and statistical analysis, ruminal EAA degradability and intestinal EAA digestibility were categorized into the following feed types: animal proteins, byproduct, concentrate protein, dry forage, energy grains, fibrous byproduct, protein fiber byproduct, silage, and seed protein, which is consistent with designations by White et al. (2017) unless no AA disappearance results were present within a feed category.

For ruminal degradability and intestinal digestibility of AA, the statistical model evaluated the effects of AA, incubation time, and feed category along with 2and 3-way interactions among these variables. When TAA was used as a covariate, the random effect of study became nonsignificant and was dropped from the model. When degradability or digestibility of AAi were expressed as ratios of TAA, the random effect of study also was not significant. Thus, random variation associated with methodological details or differences among feeds are similar for AAi as for TAA.

Ruminal degradability of EAA was not different $(P>$ $0.10)$ among times of incubation ( 12 vs. $16 \mathrm{~h}$ ) nor interactions with time except for the interaction $(P<0.01)$ of time with AA for degradability (percentage), which was not significant $(P>0.10)$ when undegradability (100\% minus degradability \%) was expressed as a ratio 
of TAA undegradability (Table 1). The interaction of individual AA with feed category $(P<0.05)$ expressed both ways supports differences in ruminal AA degradation among feeds. However, results are likely influenced by the low number of observations for feed categories (Table 2). The very low ruminal degradability for corn gluten meal (Harstad and Prestløkken, 2001), which is the only byproduct protein in our database, is potentially a result from challenges with the internal environment of the Dacron bags incubating this feed (Stern et al., 1997). Similarly, the highly variable degradabilities of individual AA for dehydrated alfalfa (Taghizadeh et al., 2005), which is the only representative of the dry forage category, also probably contributes to an unbalanced data set. The undegradability of His (proportion of TAA undegradability) tends to be lower than that of TAA (the weighted average of all recovered AA; i.e., the ratio is $<1.0$ ), whereas Met and the branched-chain AA ratios were typically higher than 1.0; Lys and Arg depended on the feed category (Table 2). In a survey of studies, Harstad and Prestløkken (2001) noted that Met and the branched-chain AA tended to have lower degradability; and Arg and Lys, higher degradability. Because His, Lys, and Met are the 3 AA most likely to be limiting in North American diets, possibly with the branched chain AA (Patton et al., 2014), future research is highly justified.

For intestinal digestibility of EAA, no effects were found for time or its interactions (Table 1). Individual AA, feed category, intestine method, and various other interactions including the 3-way interaction were significant regardless of whether intestinal digestibilities were expressed as a percentage of original AA or if these were normalized as a proportion of TAA digestibility. As with the ruminal AA degradabilities, dry forage was highly variable for intestinal AA digestibilities, perhaps because of its low replication (Table 3 ). When normalized as a proportion relative to TAA, His and Lys digestibility was $<1.0$ for energy grains. Met was generally $>1.0$ except for seed proteins. One cannot rule out bacterial AA contamination of the rumen undegraded AA (Paz et al., 2014) or potentially of the residue from mobile bags recovered in feces (Jarosz et al., 1994), although the latter authors suggested that such errors are small and might be comparable to opposing errors resulting from efflux of small particles that are not fully digestible. However, both the lower ruminal undegradability and lower intestinal digestibility of His support expectations that His can become limiting when dietary CP is limited and microbial protein makes up a greater proportion of metabolizable His (Lee et al., 2012). Further conclusions on intestinal digestibility of EAA among feeds require a more robust database.

To our knowledge, this is the first derivation of a system normalizing EAA disappearance to TAA, and some published data could not be included because authors did not provide relevant data for such calculations. Therefore, interactions and low numbers of observations among feeds prevent us from drawing firm conclusions on the differential AA degradabability and intestinal digestibility within feeds, particularly because of the limited overlap of methods within study and resulting potential for an unbalanced data set (that is, few authors replicated both methods within studies). However, as supported by the elimination of the random effect of study, we recommend for future researchers to use TAA to normalize individual EAA degradability in the rumen and subsequent intestinal digestibility. We also recommend standardizing ruminal incubation to $16 \mathrm{~h}$ and using robust approaches to remove AA from adherent bacteria in residue after ruminal exposure.

Table 1. ANOVA for factors affecting ruminal degradability and intestinal digestibility of EAA

\begin{tabular}{|c|c|c|c|c|c|c|c|c|c|c|}
\hline Variable & $\mathrm{AA}$ & Categ & Time & $\begin{array}{l}\text { Intestine } \\
\text { method }\end{array}$ & $\begin{array}{l}\text { AA } \times \\
\text { Categ }\end{array}$ & $\begin{array}{l}\mathrm{AA} \times \\
\text { time }\end{array}$ & $\begin{array}{l}\text { AA } \times \\
\text { method }\end{array}$ & $\begin{array}{l}\text { Categ } \times \\
\text { method }\end{array}$ & $\underset{\text { time }}{\mathrm{AA} \times \text { Categ }} \times$ & $\underset{\text { method }}{\mathrm{AA} \times \text { Categ } \times}$ \\
\hline \multicolumn{11}{|l|}{ Rumen $^{1}$} \\
\hline Degradability, \% & $<0.01$ & NS & NS & $\mathrm{NA}$ & $<0.01$ & $<0.01$ & NA & NA & NS & NA \\
\hline \multicolumn{11}{|l|}{ Intestine $^{2}$} \\
\hline Digestibility, \% & $<0.01$ & 0.02 & NS & NS & NS & NS & $<0.01$ & 0.01 & NS & $<0.01$ \\
\hline $\mathrm{AAi} / \mathrm{TAA}$ & $<0.01$ & $<0.01$ & NS & NS & $<0.01$ & NS & $<0.01$ & 0.07 & NS & $<0.01$ \\
\hline
\end{tabular}

${ }^{1} P$-values are from ANOVA for disappearance of individual EAA (AA effect) or disappearance from feeds grouped into feed categories (Categ) after incubation in the rumen in situ for either 12 or $16 \mathrm{~h}$ (time effect). NA = not applicable because effects were postruminal. NS: $P>0.10$. Ruminal degradabilities of individual AA (AAi) are a percentage of the respective AA in feed with a covariate for total AA (TAA) in the respective feed. To assess AAi for supply, degradabilities were converted to rumen-undegraded AA (RUAA; $100 \%$ minus degradability); the undegradability of AAi was divided by the respective total AA (TAA) undegradability from that feed. Means are reported in Table 2.

${ }^{2} P$-values are from ANOVA for disappearance of RUAA after incubation in digestive enzymes in vitro or after insertion into mobile bags inserted into the duodenum that were recovered in the ileum or feces (intestine method). NS: $P>0.10$. Intestinal digestibilities are reported as a percentage of initial individual RUAA (RUAAi), and the data were covariate-adjusted for TAA digestibility. The digestibilities of RUAAi were divided by the digestibility of the respective TAA from that feed. Means are reported in Table 3. 


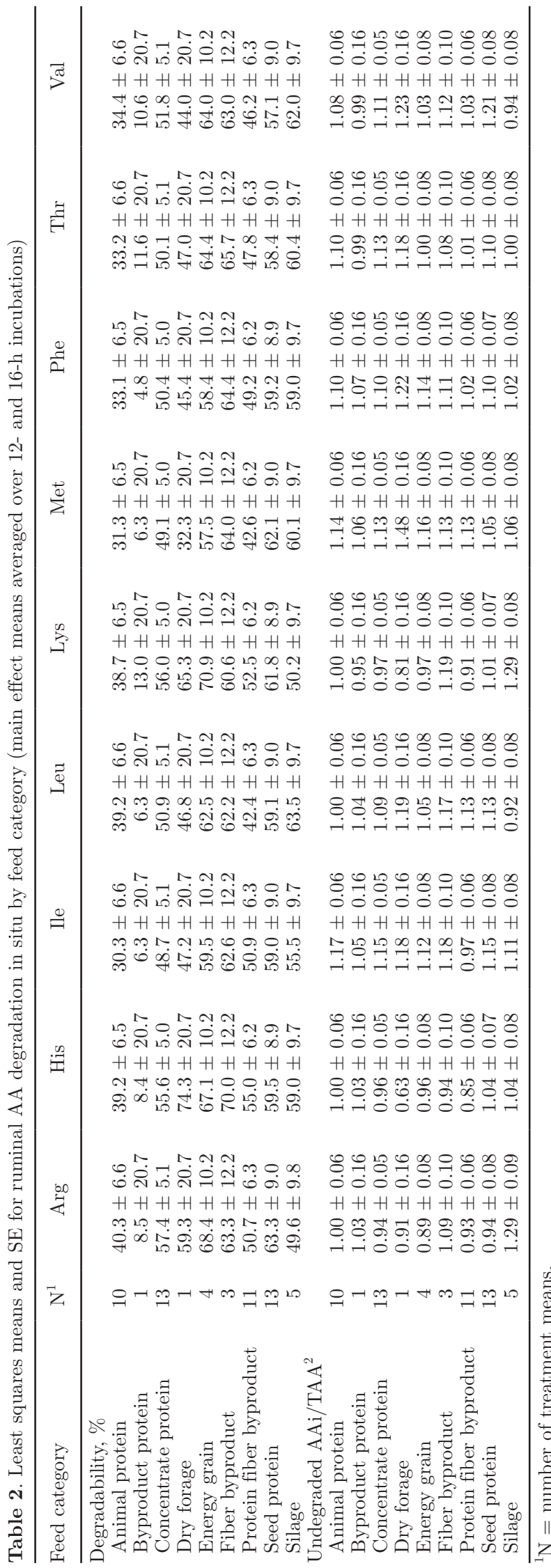

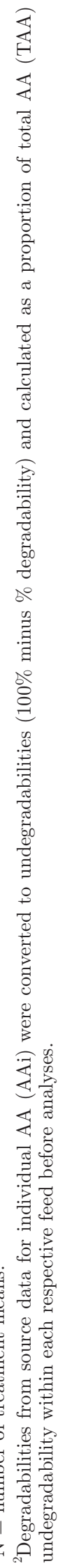

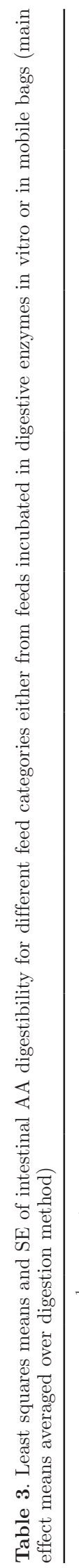

\section{ขิ $\therefore \circ 0 \dot{0} 000000$ $H+H+H+H+H$ 두유}

ิํㅇำช $\dot{0} \dot{0} \dot{0} \dot{0} \dot{0} \dot{0} \dot{0} \dot{0}$ $\mathrm{H} H+\mathrm{H} H+\mathrm{H} H \mathrm{H}$

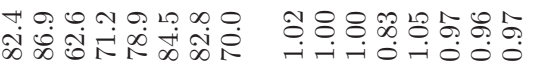

$\ln 0$ hom $\dot{\theta} \dot{0} \dot{0} \dot{0}+\dot{0} \dot{0} \dot{0}$ $H+H+H+H+H$ $\infty$ ๓ मि

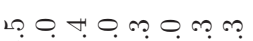

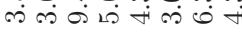
$H+H+H+H+H$

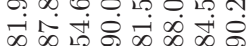

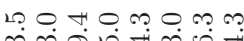

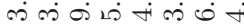
$H+H+H+H+H$ $\hat{\sim}$

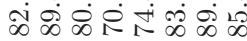

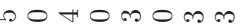
vis $H+H+H+H+H$ ำ

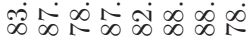

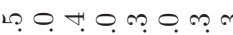
लि क्षे $H+H+H+H+H$

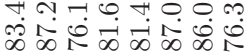

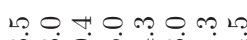

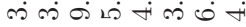
$H+H+H+H+$

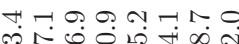

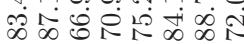

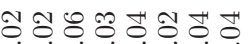
$0 \cdot 000000000$ $H+H+H H H H$

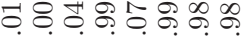
-

ㄱํㅇำ 0000000 $H+H+H+H+H$ 웅

ำ ㅇํㅇ \& $\therefore \circ \dot{0} 0 \dot{0} \dot{0} 0 \dot{0}$ $H+H+H+H+H$ ำㅇำ -

ำ ชิ

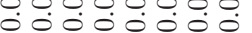
$H+H+H+H+H$ ஐ \&

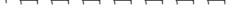

ㄱํㅇํㅇ 00000000 $H+H+H+H+H$ ๑ \& 눙 \& \& \& \&

in

ㄱํㅇํำ 00000000 $H+H H+H+H$ 붕요

우요 $H+H+H+H+H$ -i -

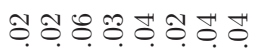

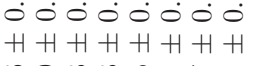

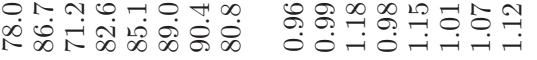

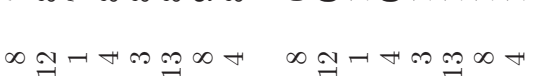
$\bar{z}$

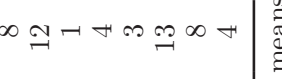

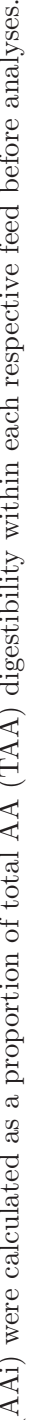

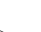

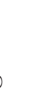

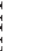


The use of in vitro incubation in digestive enzymes (Gargallo et al., 2006) has logistical benefits for laboratories lacking access to duodenally cannulated cows; moreover, when compared with in vitro incubation, we also noted that mobile bags have disadvantages of potential overestimation of digestibility with pore sizes that are too large, potential error from bacterial contamination, and moderately increased variability.

White et al. (2017) used dairy studies measuring postruminal non- $\mathrm{NH}_{3}$, nonmicrobial $\mathrm{N}$ flows to standardize prediction of RUP among the same feed classes as used herein. Similar approaches can be derived for dRUP. Based on the strong linear relationship between $\mathrm{N}$ (or CP) and TAA documented herein, the respective RUP and dRUP can be multiplied by the ratios of EAA normalized to TAA (Tables 2 and 3 ) to predict ruminal undegradability and intestinal digestibility of individual EAA. The more robust database described by White et al. (2017) for RUP and similar approaches for dRUP allow flexibility for routine laboratory assessment by commercial laboratories, which could then be converted to EAA supply, particularly if the data in Tables 2 and 3 are expanded both within and among all feed categories. Subsequent results could be integrated into a factorial metabolizable AA requirement system. The rationale described herein therefore justifies such future objectives to expand EAA and TAA degradability and digestibility in a standardized approach among laboratories, including more data for Trp.

\section{ACKNOWLEDGMENTS}

Research was supported by state and federal funds appropriated to the Ohio Agricultural Research and Development Center, The Ohio State University. Manuscript number 11/17AS.

\section{REFERENCES}

Boila, R. J., and J. R. Ingalls. 1994. The post-ruminal digestion of dry matter, nitrogen and amino acids in wheat-based distillers dried grains and canola meal. Anim. Feed Sci. Technol. 49:173-188.

Boucher, S. E., S. Calsamiglia, C. M. Parsons, H. H. Stein, M. D. Stern, P. S. Erickson, P. L. Utterback, and C. G. Schwab. 2009a. Intestinal digestibility of amino acids in rumen undegradable protein estimated using a precision-fed cecectomized rooster bioassay: I. Soybean meal and soyplus. J. Dairy Sci. 92:4489-4498.

Boucher, S. E., S. Calsamiglia, C. M. Parsons, H. H. Stein, M. D Stern, P. S. Erickson, P. L. Utterback, and C. G. Schwab. 2009b. Intestinal digestibility of amino acids in rumen-undegraded protein estimated using a precision-fed cecectomized rooster bioassay: II. Distillers dried grains with solubles and fish meal. J. Dairy Sci. 92:6056-6067.

Boucher, S. E., S. Calsamiglia, C. M. Parsons, M. D. Stern, M. Ruiz Moreno, M. Vázquez-Añón, and C. G. Schwab. 2009c. In vitro digestibility of individual amino acids in rumen-undegraded protein: The modified three-step procedure and the immobilized digestive enzyme assay. J. Dairy Sci. 92:3939-3950.

Calsamiglia, S., and M. D. Stern. 1995. A three-step in vitro procedure for estimating intestinal digestibility of protein in ruminants. J. Anim. Sci. 73:1459-1465.

Fathi Nasri, M. H., J. France, M. Danesh Mesgaran, and E. Kebreab. 2007. Effect of heat processing on ruminal degradability and intestinal disappearance of nitrogen and amino acids in Iranian whole soybean. Livest. Sci. 113:43-51.

Gargallo, S., S. Calsamiglia, and A. Ferret. 2006. Technical note: A modified three-step in vitro procedure to determine intestinal digestion of proteins. J. Anim. Sci. 84:2163-2167.

Harstad, O. M., and E. Prestløkken. 2000. Effective rumen degradability and intestinal indigestibility of individual amino acids in solvent-extracted soybean meal (SBM) and xylose-treated SBM (Soypass ${ }^{\circledR}$ ) determined in situ. Anim. Feed Sci. Technol. 83:31-47.

Harstad, O. M., and E. Prestløkken. 2001. Rumen degradability and intestinal indigestibility of individual amino acids in corn gluten meal, canola meal and fish meal determined in situ. Anim. Feed Sci. Technol. 94:127-135.

Hvelplund, T. 1985. Digestibility of rumen microbial protein and undegraded dietary protein estimated in the small intestine of sheep and by in sacco procedure. Acta Agric. Scand. A Anim. Sci. $25: 132-144$

Jarosz, L., T. Hvelplund, M. R. Weisbjerg, and B. B. Jensen. 1994 True digestibility of protein in the small intestine and the hind gut of cows measured with the mobile bag technique using ${ }^{15} \mathrm{~N}$-labelled roughage. Acta Agric. Scand. A Anim. Sci. 44:146-151.

Lee, C., A. N. Hristov, T. W. Cassidy, K. S. Heyler, H. Lapierre, G. A. Varga, M. J. de Veth, R. A. Patton, and C. Parys. 2012. Rumenprotected lysine, methionine, and histidine increase milk protein yield in dairy cows fed a metabolizable protein-deficient diet. J. Dairy Sci. 95:6042-6056.

Ljøkjel, K., O. M. Harstad, and A. Skrede. 2000. Effect of heat treatment of soybean meal and fish meal on amino acid digestibility in mink and dairy cows. Anim. Feed Sci. Technol. 84:83-95.

Patton, R. A., A. N. Hristov, and H. Lapierre. 2014. Protein feeding and balancing for amino acids in lactating dairy cattle. Vet. Clin. North Am. Food Anim. Pract. 30:599-621.

Paz, H. A., T. J. Klopfenstein, D. Hostetler, S. C. Fernando, E. Castillo-Lopez, and P. J. Kononoff. 2014. Ruminal degradation and intestinal digestibility of protein and amino acids in high-protein feedstuffs commonly used in dairy diets. J. Dairy Sci. 97:64856498

Stern, M. D., A. Bach, and S. Calsamiglia. 1997. Alternative techniques for measuring nutrient digestion in ruminants. J. Anim. Sci. 75:2256-2276.

Taghizadeh, A., M. Danesh Mesgaran, R. Valizadeh, F. E. Shahroodi, and K. Stanford. 2005. Digestion of feed amino acids in the rumen and intestine of steers measured using a mobile nylon bag technique. J. Dairy Sci. 88:1807-1814.

White, R. R., Y. Roman-Garcia, J. L. Firkins, P. J. Kononoff, M. J. VandeHaar, H. Tran, T. McGill, R. Garnett, and M. D. Hanigan. 2017. Evaluation of the 2001 Dairy NRC and derivation of new prediction equations. 2. Rumen degradable and undegradable protein. J. Dairy Sci. 100. https://doi.org/10.3168/jds.2015-10801. 